\title{
Hybrid surgery in treatment of pulmonary sequestration with abdominal aorta feeding vessel: a case report
}

\author{
Haining Zhou' ${ }^{1,2}$, Shoujun Tang ${ }^{2,3}$, Quanshui Fu², Li Yu ${ }^{2}$ and Lunxu Liu ${ }^{1 *}$ (D)
}

\begin{abstract}
Background: Pulmonary sequestration is a rare congenital pulmonary dysplasia, which requires surgical resection (either via open thoracotomy or video-assisted thoracoscopic surgery [VATS] or via endoluminal occlusion of the abnormal feeding vessel).

Case presentation: We described a 51-year-old female patient with a history of recurrent cough and repeated pneumonia. She was referred to our hospital for further work-up of pulmonary sequestration. We performed a hybrid surgery (i.e., embolization of the aberrant feeding vessel of the sequestration combined with wedge resection of the left lower lobe lesion through VATS). The patient was discharged on the sixth postoperative day in good condition and without complications.
\end{abstract}

Conclusions: We believe that a hybrid operation is safer, more feasible, and more comprehensive than other treatments.

Keywords: Pulmonary sequestration, Hybrid surgery, Video-assisted thoracoscopic surgery [VATS], Embolization

\section{Background}

Pulmonary sequestration (PS) can cause recurrent infection and haemoptysis and contrast enhanced computer tomography (CT) is frequently used for the imaging diagnosis of PS so far. Moreover, the gold standard for PS diagnosis is digital subtraction angiography (DSA) or to find the abnormal feeding artery during surgery. Currently, embolism, ligation of the abnormal feeding artery and resection of the diseased lung tissue are performed to treat PS [1]. In this case report, we present a patient with PS successfully treated through a hybrid operation.

\section{Case presentation}

A 51-year-old female patient was admitted to our hospital because of recurrent cough and expectoration for 2 years. Her condition recurred several times intermittently and was exacerbated 7 days before her hospitalization. The patient had no history of smoking, chronic bronchitis or pulmonary tuberculosis. Plain chest $\mathrm{CT}$ images showed para-aortic opacities in the left

\footnotetext{
* Correspondence: liulunxu@aliyun.com

${ }^{1}$ Department of Thoracic surgery, West China Hospital, Sichuan University,

Chengdu 610000, China

Full list of author information is available at the end of the article
}

lower lobe. Furthermore, fiberoptic bronchoscopy and abdominal colour Doppler ultrasound showed no significant abnormalities. However, the re-examination of contrast-enhanced chest CT revealed a $45 \mathrm{~mm} \times 41 \mathrm{~mm}$ opacity in the left lower lobe and a feeding vessel was found connected to the abdominal aorta. Thus, a tentative diagnosis of PS was made (Fig. 1).

After completion of preoperative preparation, first the patient underwent an isolated feeding artery embolization under local anaesthesia in the hybrid operating room. A $5 \mathrm{~F}$ catheter was inserted by Seldinger technique along the right femoral artery. The contrast catheter was selectively inserted into the feeding artery of the left lower lobe PS to perform DSA. Contrast medium was observed in the left cardiophrenic angle and the feeding artery was significantly thickened. Spring rings with different specifications were pushed through the catheter until embolism was satisfactory. Afterward, under general anaesthesia and double-lumen intubation, with the patient in the right decubitus position, a wedge resection of the PS was performed by VATS. A 4-mm aberrant branch from the abdominal aorta was seen to ascend through the diaphragm into the chest to feed the PS. The artery was carefully dissected, ligated with Hem- 

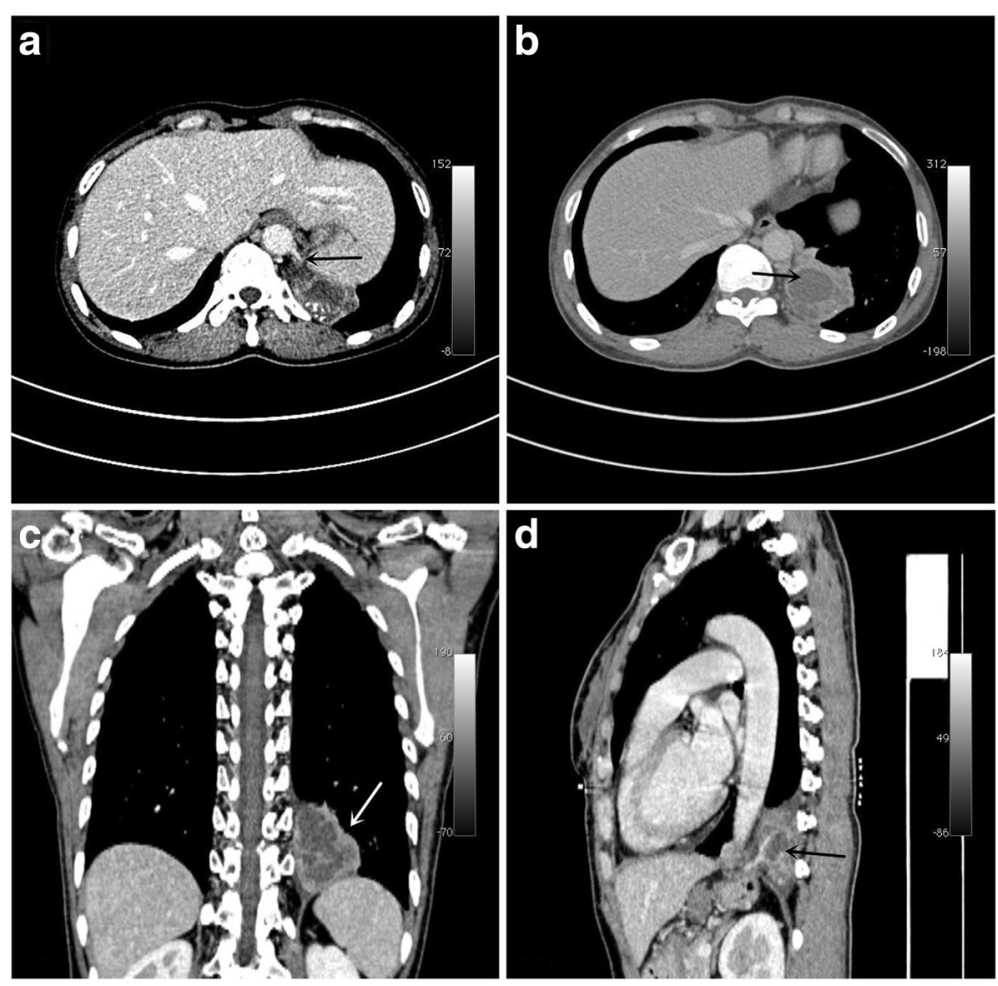

Fig. 1 a Enhanced CT scan: abnormal blood vessels from the abdominal aorta; $\mathbf{b}$ mass and abnormal blood vessels in the mediastinum; c coronal plane; and $\mathbf{d}$ sagittal plane

o-lock avoiding the site of the spring coil to ensure proper closure of the artery, and cut. Finally, a wedge resection of the diseased lung was performed with staplers (Fig. 2). Pathological examination of the resected specimen verified the diagnosis of PS. Postoperative course was uneventful and the patient was discharged on the sixth postoperative day.

\section{Discussion}

The diagnosis of PS mainly depends on the presence of an abnormal feeding artery. The contrast-enhanced CT often shows the feeding artery originating from the aorta
[2]. Among the total blood supplied, 70\% originates from the thoracic aorta. In the case herein reported, the feeding artery originated from the abdominal aorta. Intralobar PS shares a common visceral pleura with the surrounding lung tissue and has pathological communication with normal bronchi. Thus, repeated infection and haemoptysis are observed during the development of the disease.

PS is mainly treated by resection. In adult patients or children who cannot tolerate surgery, embolization can be used. However, embolization alone with no resection of the PS is unsuitable for patients who have multiple feeding

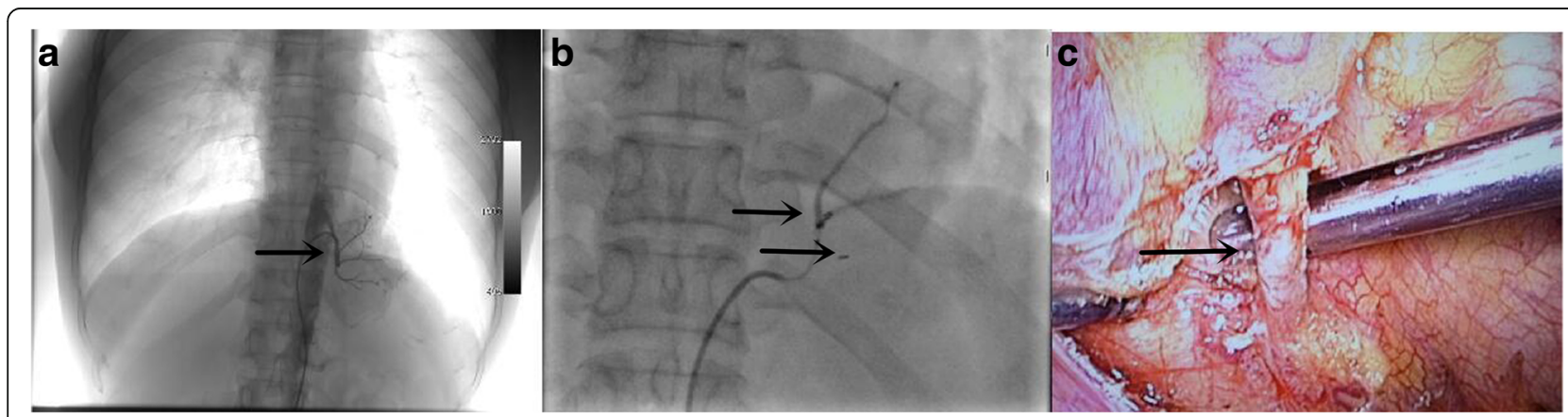

Fig. 2 a Angiography of the aberrant artery before the interventional embolization; $\mathbf{b}$ after the interventional embolization; and $\mathbf{c}$ the aberrant artery clipped by VATS 
arteries or prolonged and repeated infections before the operation. Presently, most patients undergo either resection or non-surgical methods. Up to now, few cases of endovascular embolization combined with VATS resection of PS have been reported. Avsenik and colleagues reported a case of PS with aneurysmal feeding vessel. Thoracic endovascular aortic repair was performed primarily and, secondarily, a right lower lobectomy was performed. Bhatt and Deutsch described a case of coil embolization of the feeding systemic vessel earlier the day before the planned VATS procedure [3-5]. In this case, a patient with chronic infection experienced pain, discomfort, and other symptoms. Complete removal of the focus of infection in the diseased lung is difficult and can easily induce more infection. A single interventional treatment cannot completely address this problem. Moreover, the feeding artery originates from the abdominal aorta and has systemic pressure. In addition, in the anomalous artery, the muscle fibers are lesser than in the normal arteries and are thus susceptible to tearing, which can lead to massive bleeding or retraction into the peritoneum. A hybrid operation not only can help us clarify the diagnosis and discover the presence and characteristics of the abnormal feeding artery and its branches, but also can facilitate the next step of the surgical procedure. Furthermore, as prolonged and repeated infections could inevitably lead to pleural and diaphragmatic adhesions, a hybrid operation can effectively assist the surgeons in such a way that they can avoid overlooking small branches or causing massive bleeding, thus ensuring the safety of the operation. Compared with a single operation or a single non-surgical procedure, hybrid surgery has broader indications and thus it is more efficient, accurate, and comprehensive. In addition, intraoperative and postoperative complications are relatively few.

\section{Conclusions}

In patients diagnosed with PS who present with a long course of the disease and repeated infections, the lesion is often surrounded by sever adhesions. Moreover, the highpressured feeding artery from the aorta is highly susceptible to tearing because of inadequate muscle fibers. Thus, for the prevention of catastrophic consequences of an intraoperative accidental injury (such as massive bleeding caused by feeding artery retraction into the peritoneum), we believe that a hybrid operation is safer, more feasible, and more comprehensive than other treatments.

\section{Abbreviations}

CT: Computer tomography; DSA: Digital subtraction angiography;

PS: Pulmonary sequestration; VATS: Video-assisted thoracoscopic surgery

\section{Acknowledgements}

The authors are indebted to Dr. Ramon Rami-Porta, from the Department of Thoracic Surgery of Hospital Universitari Mutua Terrassa, in Terrassa, Spain, for his revision of the original manuscript and thoughtful suggestions.
Availability of data and materials

All data generated or analysed during this study are included in the published article.

Authors' contributions

LXL, HNZ and SJT were involved in patient care. SJT, LY and QSF were involved in manuscript preparation and revisions. All authors read and approved the final manuscript.

\section{Ethics approval and consent to participate}

The patient provided full consent for the publication of the data. The need for ethics approval was not required describing this case.

\section{Consent for publication}

Written informed consent was obtained from the patient for publication of this case report and any accompanying images. A copy of the written consent is available for review by the Editor-in-Chief of this journal.

\section{Competing interests}

The authors declare that they have no competing interests.

\section{Publisher's Note}

Springer Nature remains neutral with regard to jurisdictional claims in published maps and institutional affiliations.

\section{Author details}

'Department of Thoracic surgery, West China Hospital, Sichuan University, Chengdu 610000, China. ${ }^{2}$ Department of Thoracic surgery, Suining Central Hospital, Suining 629000, China. '3Shehong People's Hospital, Suining 629000, China.

Received: 28 December 2017 Accepted: 9 May 2018

Published online: 18 May 2018

References

1. Seong YW, Kang CH, Kim JT, Moon HJ, Park IK, Kim YT. Video-assisted thoracoscopic lobectomy in children: safety, efficacy, and risk factors for conversion to thoracotomy. Ann Thorac Surg. 2013;95(4):1236-42.

2. Walker CM, Wu CC, Gilman MD, Godwin JD, Shepard JA, Abbott GF. The imaging spectrum of bronchopulmonary sequestration. Curr Probl Diagn Radiol. 2014:43(3):100-14.

3. Hewett L, Kwon J, Adams JD, Denlinger CE, Klapper JA. Intralobar pulmonary sequestration with aneurysmal feeding vessel: use of hybrid surgical management. Ann Thorac Surg. 2016;102(6):e533-5.

4. Avsenik J, Stupnik T, Popovic P. Endovascular embolization prior to surgical resection of symptomatic intralobarpulmonarysequestration in an adult. Eur J Radiol Open. 2015;9(3):12-5.

5. Bhatt JM, Deutsch LS, Calhoun RF, Cooke DT. Video assisted thoracic surgery sublobar resection of intralobar pulmonary sequestration after preoperative embolization of systemic blood supply. Multimed Man Cardiothorac Surg. 2010;2010(709):mmcts.2009.004218) https://doi.org/10. 1510/mmcts.2009.004218.

Ready to submit your research? Choose BMC and benefit from:

- fast, convenient online submission

- thorough peer review by experienced researchers in your field

- rapid publication on acceptance

- support for research data, including large and complex data types

- gold Open Access which fosters wider collaboration and increased citations

- maximum visibility for your research: over 100M website views per year

At BMC, research is always in progress.

Learn more biomedcentral.com/submissions 